\title{
Distance Determination of Mass Losing Carbon Stars from CO and HCN Radio Observations
}

\author{
Wasaburo Unno ${ }^{1}$, Takashi Tsuji ${ }^{2}$, Kou-ichi Koyama ${ }^{1}$, Hideyuki Izumiura ${ }^{3}$, \\ Nobuharu Ukita ${ }^{2}$, and Norio Kaifu ${ }^{2}$ \\ 1 Kinki University, Higashi-Osaka, Osaka 577. ${ }^{2}$ Tokyo Astronomical Observatory, Mitaka, Tokyo 181 \\ 3 Department of Astronomy, University of Tokyo, Tokyo 113
}

\begin{abstract}
A method of distance determination of evolved carbon stars is proposed and applied to six stars for which the terminal velocity of expansion and the angular size are obtained from the $\mathrm{CO}$ and $\mathrm{HCN}$ radio observations made at the Nobeyama Radio Observatory. The method assumes the radiation driven wind in spherical geometry. Within those small samples, however, two types of mass losing stars that are systematically different in the antenna temperature ratio $T_{A}(\mathrm{CO}) / T_{A}(\mathrm{HCN}) \gtrless 1$, in the velocity ratio $v(\mathrm{CO}) / v(\mathrm{HCN}) \lessgtr 1$, and in the angular size ratio $\theta(\mathrm{CO}) / \theta(\mathrm{HCN}) \gtrless 1$ seem to be present, suggesting nonspherical geometry of the outflow.
\end{abstract}

\$1. Distance Determination of Evolved Carbon Stars In astrophysics, little can be understood without the knowledge of the distance. The determination of mass-loss rate from evolved carbon stars depends also on the distance determination. For red giant stars especially for pulsating variables, the distance determination may be fairly reliable. However, about a half of the mass-losing carbon stars that are mainly IRC and CRL objects are infrared objects, for which the usual distance determination is not feasible except through the kinematic or similar rough assumptions, e.g., $L=10^{4} L_{\odot}$. The principle for distance determination is based on the radiation driven stellar wind solution for which the velocity $v$ is given by,

$$
v^{2}=\frac{\eta}{2 \pi} \frac{\kappa L}{c r_{c}}, \quad\left(r \gg r_{c}\right)
$$

where $\eta$ denotes the efficiency factor taking care of the change in the dust opacity $\kappa\left(\right.$ at $\left.r \geq r_{c}\right)$, $L$ the luminosity, and $r_{c}$ the sonic point radius assumed to be equal to the dust formation radius. Observations give $v, F_{b o l}\left(=L / 4 \pi d^{2}\right)$, and the angular size $\theta$ ( the source radius $r_{t}=\theta d$ ), where $d$ denotes the distance. We have approximately $\left(r_{t} / r_{c}\right)^{3}=\left(T_{d} / T_{t}\right)^{4}$ from the radiation transfer, where $T_{d}\left(\sim 10^{3} \mathrm{~K}\right)$ and $T_{t}(\sim 10 \mathrm{~K})$ denote the dust formation temperature and the molecular shell temperature at $r_{t}$. Then, we obtain

$$
d=d_{0} \frac{\theta v^{2}}{F} \quad \text { where } \quad d_{0}=\frac{1}{2 \eta} \frac{c}{\kappa}\left(\frac{T_{t}}{T_{d}}\right)^{4 / 3} .
$$
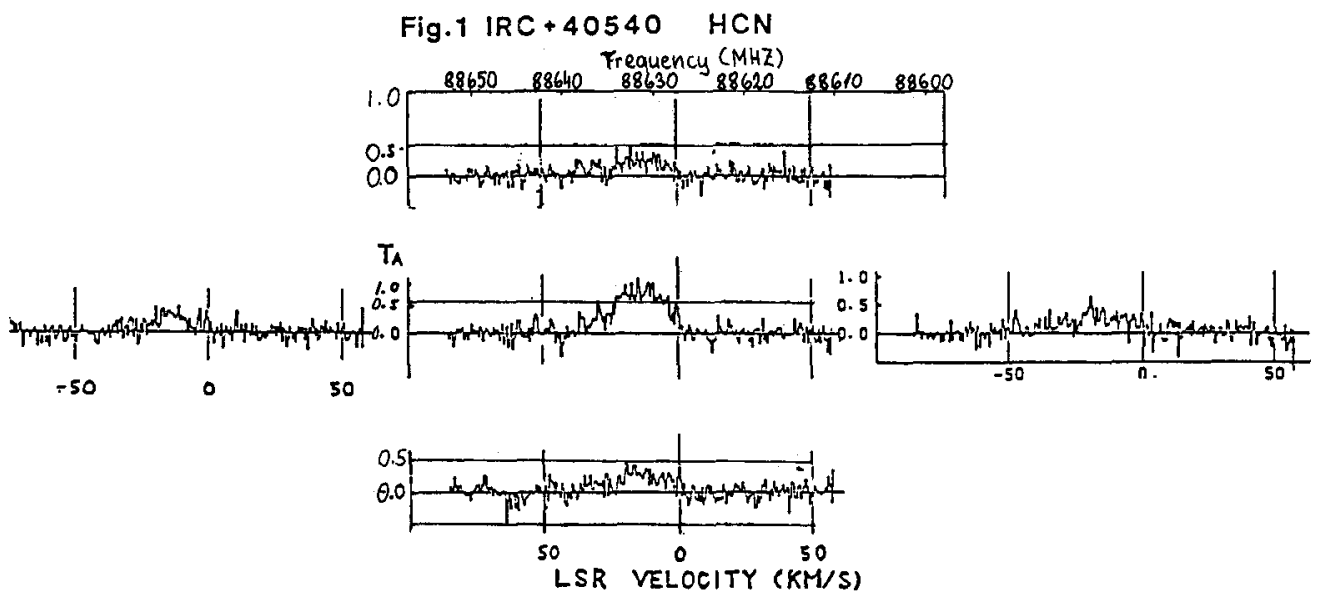
Fig. 1 shows just one example of the five point observation (each separated by 15 " from the neighboring point) of $\mathrm{HCN}(\mathrm{J}=1-0)$. The terminal velocity $v$ is read directly from such tracings. The angular size $\theta$ is obtained from the deconvolution of the Gaussian fit of the observed peak intensities with the antenna beam profile assumed to be also Gaussian. Two $\theta$ values are obtained from the N-S and E-W comparisons and they are averaged. The discrepancy between this and the true $\theta$ corresponding to the edge may be absorbed in the efficiency factor $\eta$. Table 1 shows the result for $d_{0}=4.0 \times 10^{7} \mathrm{~g} \mathrm{~cm}^{-1} \mathrm{~s}^{-1}$ The value of $d$ is apparently too large for IRC+00365, and for CRL1922. Futher improvement of the method is now in progress.

Table 1.

\begin{tabular}{|c|c|c|c|c|c|c|c|c|c|}
\hline Name & $m_{b o l}$ & line & $T_{A}(\mathrm{~K})$ & $v\left(\frac{\mathrm{km}}{\mathrm{s}}\right)$ & $\theta_{N S} "$ & $\theta_{E W "}$ & $\theta "$ & $d(\mathrm{kpc})$ & Type \\
\hline $\mathrm{IRC}+00365$ & +5.31 & $\begin{array}{r}\mathrm{CO} \\
\mathrm{HCN}\end{array}$ & $\begin{array}{l}0.20 \\
0.55\end{array}$ & $\begin{array}{l}35.2 \\
37.3\end{array}$ & $\overline{8.9}$ & $\overline{7.2}$ & $\begin{array}{r}12.7 \\
9.0\end{array}$ & $\begin{array}{l}48 \\
38\end{array}$ & I \\
\hline $\mathrm{IRC}+10216$ & +0.51 & $\begin{array}{c}\mathrm{CO} \\
\mathrm{HCN}\end{array}$ & $\begin{array}{l}4.53 \\
9.00\end{array}$ & $\begin{array}{l}16.6 \\
15.4\end{array}$ & $\begin{array}{l}19.9 \\
24.4\end{array}$ & $\begin{array}{l}22.6 \\
22.6\end{array}$ & $\begin{array}{l}21.3 \\
23.5\end{array}$ & $\begin{array}{l}0.22 \\
0.16\end{array}$ & I \\
\hline $\mathrm{IRC}+10401$ & +4.51 & $\begin{array}{c}\mathrm{CO} \\
\mathrm{HCN}\end{array}$ & $\begin{array}{l}0.11 \\
0.27\end{array}$ & $\begin{array}{l}29.4 \\
28.5\end{array}$ & - & $\begin{array}{r}13.5 \\
8.1\end{array}$ & $\begin{array}{r}13.5 \\
8.1\end{array}$ & $\begin{array}{l}0.71 \\
0.90\end{array}$ & I \\
\hline $\mathrm{IRC}+40540$ & +4.39 & $\begin{array}{c}\mathrm{CO} \\
\mathrm{HCN}\end{array}$ & $\begin{array}{l}0.72 \\
0.75\end{array}$ & $\begin{array}{l}14.2 \\
18.5\end{array}$ & $\begin{array}{r}18.8 \\
6.7\end{array}$ & $\begin{array}{r}17.6 \\
7.6\end{array}$ & $\begin{array}{r}18.2 \\
7.2\end{array}$ & $\begin{array}{l}0.48 \\
0.32\end{array}$ & II \\
\hline IRC +50096 & +4.24 & $\begin{array}{c}\mathrm{CO} \\
\mathrm{HCN}\end{array}$ & $\begin{array}{l}0.42 \\
0.34\end{array}$ & $\begin{array}{l}16.1 \\
17.2\end{array}$ & $\begin{array}{l}17.2 \\
20.3\end{array}$ & $\begin{array}{r}11.8 \\
3.4\end{array}$ & $\begin{array}{l}14.6 \\
13.7\end{array}$ & $\begin{array}{l}4.5 \\
4.8\end{array}$ & II \\
\hline CRL 1922 & +5.95 & $\begin{array}{c}\mathrm{CO} \\
\mathrm{HCN}\end{array}$ & $\begin{array}{l}0.47 \\
0.33\end{array}$ & $\begin{array}{l}18.7 \\
20.4\end{array}$ & $\begin{array}{r}17.2 \\
4.2\end{array}$ & $\begin{array}{r}13.5 \\
4.2\end{array}$ & $\begin{array}{r}15.7 \\
4.2\end{array}$ & $\begin{array}{r}31 \\
9.6\end{array}$ & II \\
\hline
\end{tabular}

The antenna temperature $T_{A}$ listed above is for the $45 \mathrm{~m}$ radio telescope having beam size $17 \pm 1 "$, aperture efficiency $26 \pm 3 \%$ and beam efficiency $45 \pm 5 \%$ at $115 \mathrm{GHz}$ and $24 \pm 1 ", 37 \pm 3$ $\%$, and $68 \pm 5 \%$ at $86 \mathrm{GHz}$.

§2. Are There Two Types of Mass Losing Carbon Stars? Three stars IRC+00365, IRC+10216, and IRC+10216 belonging to Type I given in the last column of Table 1 show $T_{A}(\mathrm{CO}) / T_{A}(\mathrm{HCN}) \leq 1, v(\mathrm{CO}) / v(\mathrm{HCN}) \geq 1$ but $\theta(\mathrm{CO}) / \theta(\mathrm{HCN}) \leq 1$, and the other three stars IRC+40540, IRC+50096, and CRL 1922 belonging to Type II show the opposite tendency. Such strange tendency (cf. Nguyen-Q-Rieu et al., 1987) is difficult to understand if the spherically symmetric geometry should be assumed. Further study is required.

\section{Reference}

Nguyen-Q-Rieu, N. Epchtein, Truong-Bach and M. Cohen, Astron.Astrophys. 180,117,1987 